\title{
WELDED SLENDER STAINLESS STEEL I-BEAMS
}

\author{
M. Šorf*, M. Jandera**
}

\begin{abstract}
This paper shows starting research of welded I section beams subjected to lateral-torsional buckling. Difference in behaviors of stainless steel beams and common carbon steel beams is generally expected. To show behavior of the stainless steel beams, a simple study using advanced numerical model (GMNIA) in FE software Abaqus was carried out for cross-section with different slenderness. Results provided by the study were compared to the existing design procedures according to the Eurocodes and confirmed previous assumptions. For validation of numerical model, there were designed tests considering two types of stainless steel. A parametric study based on the validated numerical models will be used for development of a new accurate and safe design procedure.
\end{abstract}

Keywords: stainless steel, slender beam, welded beam, lateral-torsional buckling, numerical modelling

\section{Stainless steel}

Stainless steel is a specific type of steel which is corrosion and heat resistant containing a minimum of $10,5 \%$ chromium. Nowadays exist three types of stainless steels suitable for structural applications, namely austenitic, ferritic and duplex (austenitic-ferritic) stainless steel. These groups are different in strength, ductility, weldability, toughness and the ability to resist different corrosive environment as result of using various alloying elements in different amounts. There is also significant differences in material costs and availability between the stainless steel grades.

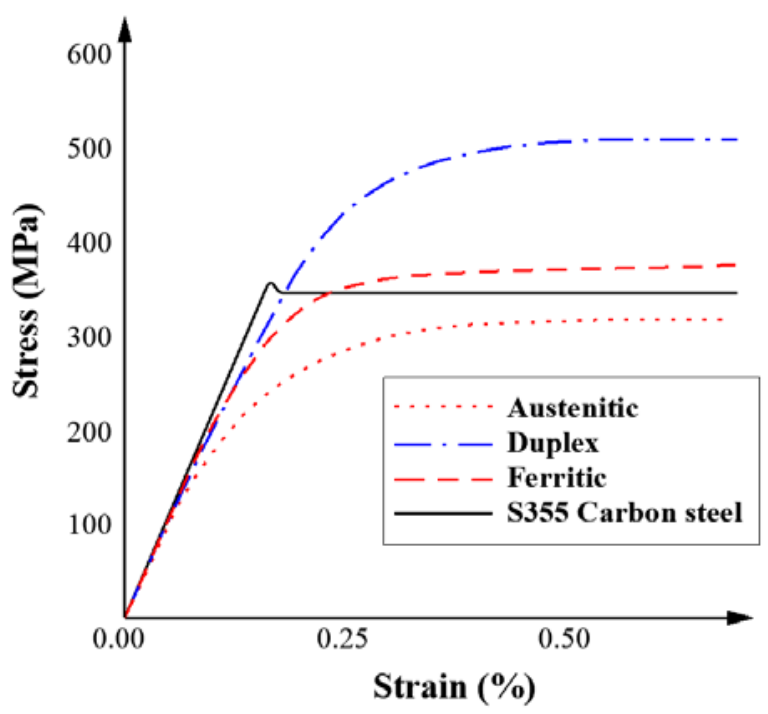

Fig. 1: Stress-strain curve for stainless steel and carbon steel

Ing. Marek Šorf: Faculty of Civil Engineering, Czech Technical University in Prague, Thákurova 7; 166 29, Prague 6; CZ, marek.sorf@fsv.cvut.cz

** doc. Ing. Michal Jandera, Ph.D.: Faculty of Civil Engineering, Czech Technical University in Prague, Thákurova 7; 166 29, Prague 6; CZ, michal.jandera@fsv.cvut.cz 
The most important difference from carbon steel is in the shape of the stress-strain curve (Fig. 1). Whereas a common carbon steel typically exhibits linear elastic behaviour up to the yield strength followed by a plastic plateau before strain hardening is encountered, stainless steel has a more rounded response with no clearly defined yield strength. The material nonlinearity is the reason for the need of other design procedures for stainless steel structures.

\section{Numerical model}

A numerical model was also used for design of test arrangements. The geometrically and materially nonlinear analysis with imperfection (GMNIA) was made in software Abaqus using shell element S4R (fournode shell element with reduced integration). The section resp. member imperfections were assumed by the lowest elastic buckling eigenmode (Fig. 2) for local resp. global buckling. The amplitudes of imperfections were specified according to EN 1993-1-5. The geometric imperfection was considered as 0.8 of the fabrication tolerance. Calculation is shown in (1):

$$
\Delta_{1}=0,8 * b / 100
$$

where $b$ is the height of the web. The amplitude of global imperfection was determined also as 0.8 of the fabrication tolerance shown in (2):

$$
\Delta_{2}=0,8 * \mathrm{~L} / 750
$$

where $L$ is the distance between two cross-section where lateral torsional buckling is prevented. The amplitude for eigenmode with greater value of $\alpha_{\text {cr }}$ was reduced by 0.7 times as also suggested in EN 1993-1-5.

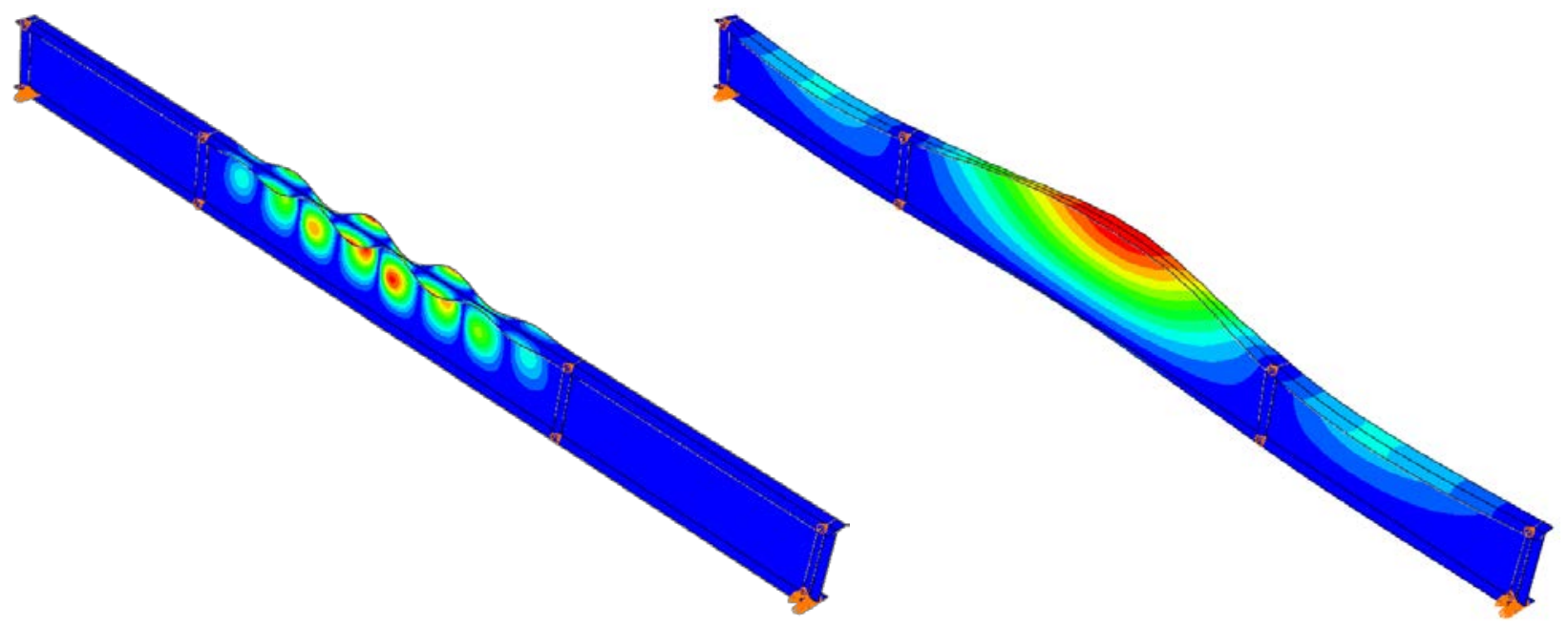

Fig. 2: Buckling mode shapes - local (left) and global (right)

\section{Test arrangement}

The experimental program is consisted of 6 four point bending tests. There was designed only one cross section made of two types of stainless steel and three different lengths. Summary of beams is given in Fig. 3, where the section geometry, classification, section and beam slenderness is specified.

The test arrangement is identical for all the beams (Fig. 4). Only the beam length and distances between constraints is different. This equipment respect boundary conditions based on the numerical analysis. It consists of simply supported beam, lateral restraints and a load-distributing beam. For all tests, the beam is supported at its ends under the lower flange. Lateral restraints are used at the ends and the points of loading for both the upper and lower flange. The arrangement is similar to the one used by Prachar et al. The results of the tests and numerical model validation will be presented on the conference. 


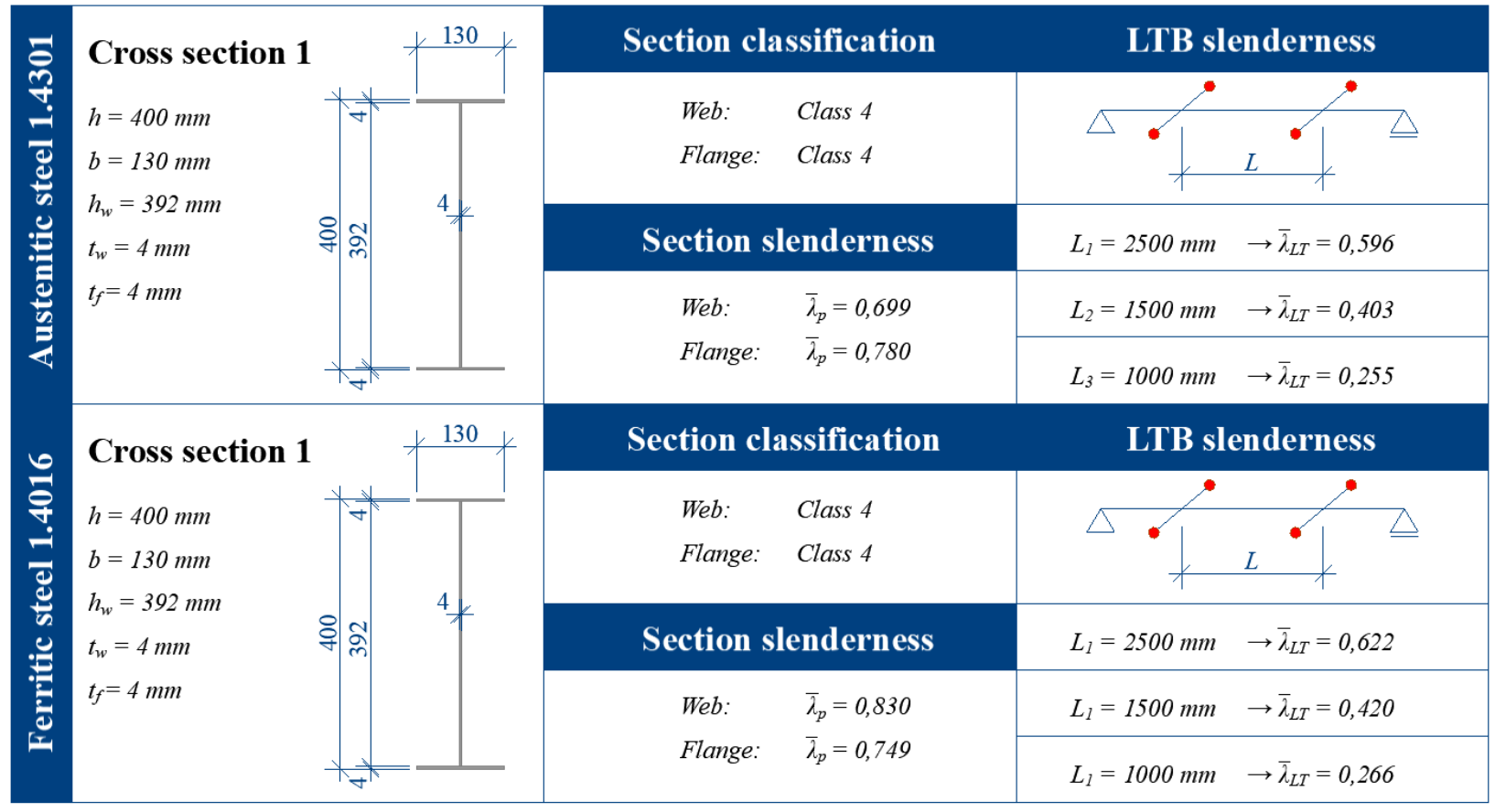

Fig. 3: Test program overview

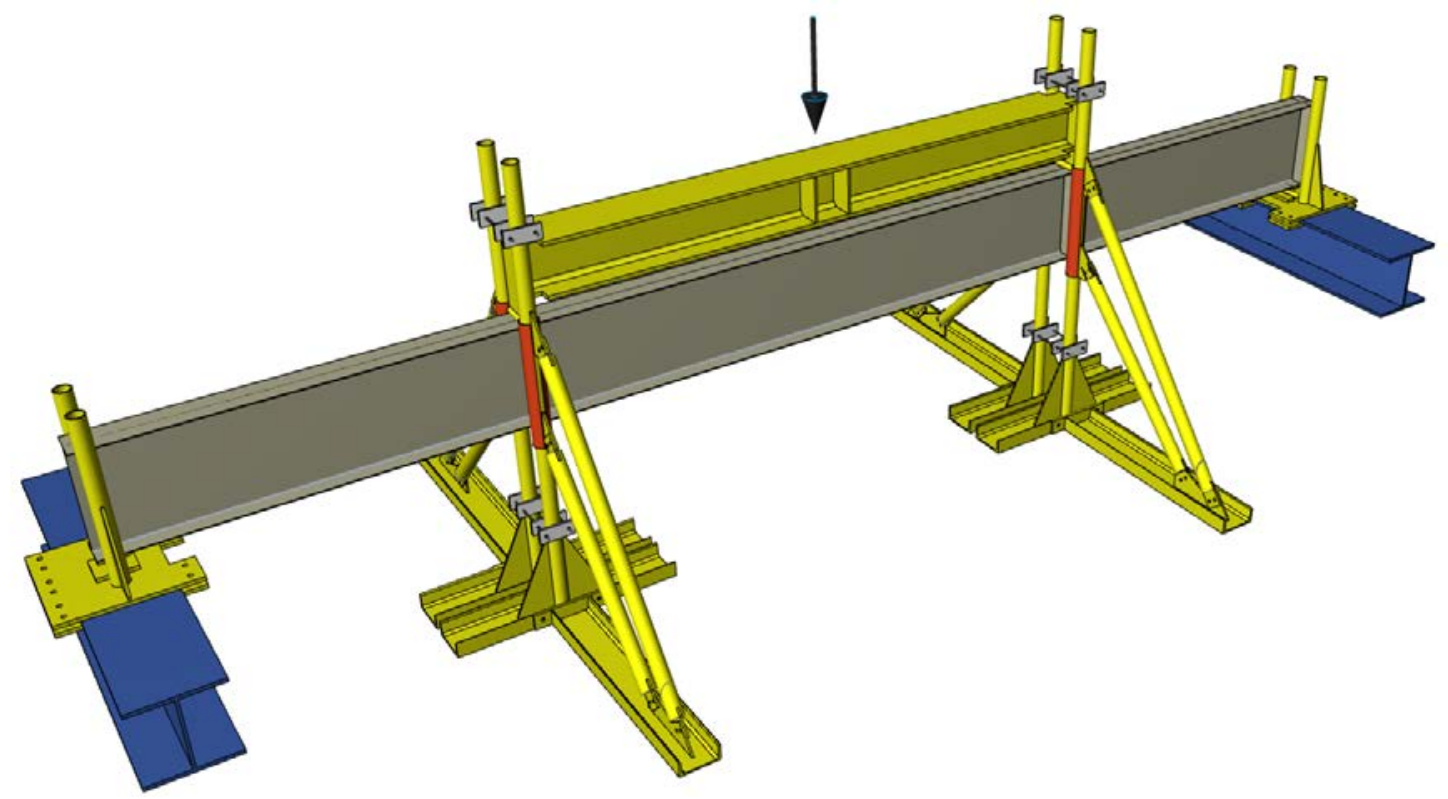

Fig. 4: The test arrangement

\section{Current design procedures}

Generally, open cross sections subjected to bending around the major axis with unrestrained or partly restrained compressed flange or compressed web tend to fail with influence of lateral torsional (global) buckling. Whereas slender cross section resistance may be governed by plate (local) buckling. Both phenomena influence significantly design of steel beams.

The resistance of beam subjected to lateral-torsional buckling should be determined according to EN 1993-1-4 from (3):

$$
M_{b, R d}=\chi_{L T} W_{y} f_{y} / \gamma_{M 1}
$$

where $\chi_{L T}$ is a reduction factor accounting for lateral torsion buckling

$W_{y}$ is $W_{p l, y}, W_{e l, y}$ or $W_{e f f, y}$ (depends on cross section class)

$f_{y}$ is the yield strength. 
For determination of $\chi_{L T}$ an imperfection factor $\alpha_{L T}$ is needed. As far as the authors are aware, there are no experimental data supporting the codified value of the factor for welded open sections. Therefore the formula (1) was compared to numerical models for three types of profiles (Fig. 5) loaded by uniform bending moment.

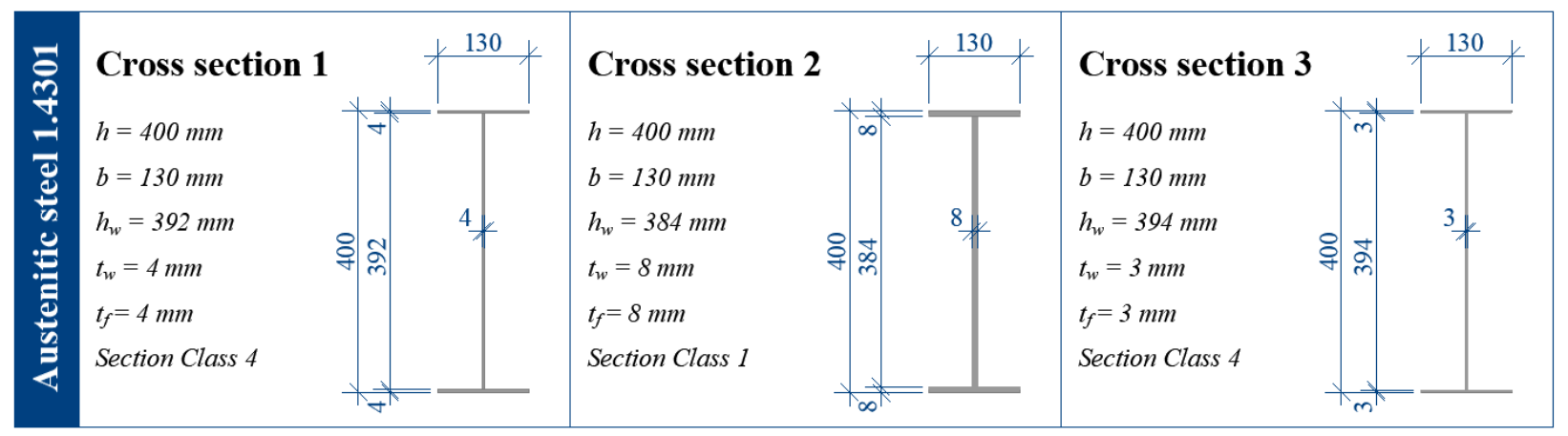

Fig. 5: Three types of profiles

Results of the study are shown below (Fig. 6) for several member lengths. The evaluation showed that the design procedure is in some cases inaccurate and unsafe.

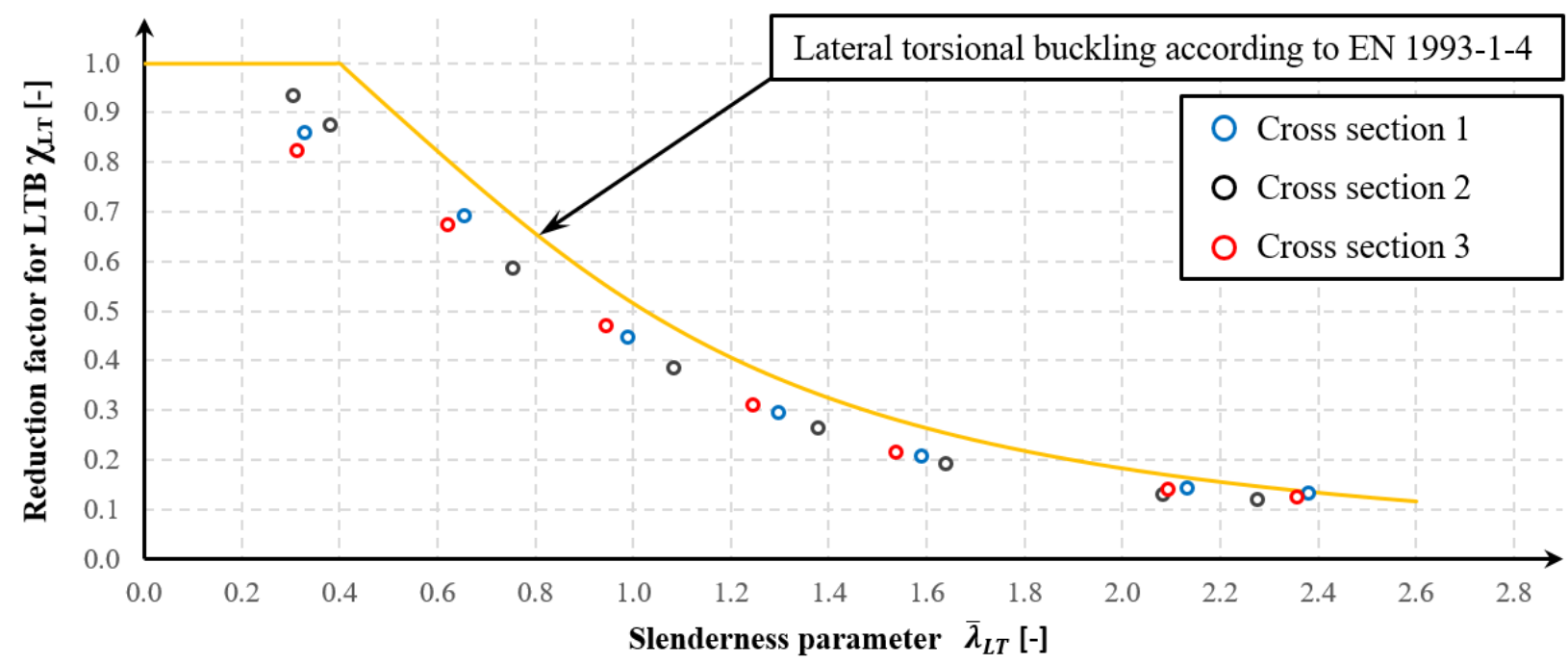

Fig. 6: Results of the study

\section{Conclusions}

This paper is focused on behavior of unrestrained welded slender stainless steel open section members subjected to bending moment around the major axis. Results of numerical models were compared to design procedures according to EN 1993-1-4 and the investigation showed significant differences. Therefore tests were designed to confirm the correctness of the numerical model in Abaqus. It assumes that a successful validation of experiments will be presented in conference.

\section{Acknowledgement}

The support of the GAČR 17 - 24769S "Nonlinear stability and strength of slender structures with nonlinear material properties” are gratefully acknowledged.

\section{References}

EN 1993-1-4 (2006) Eurocode 3: Design of steel structures - Part 1-4: General rules - Supplementary rules for stainless steel, CEN, Brussel.

Prachař, M., Hricák, J., Jandera, M., Wald, F., Zhao, B.: Experiments of Class 4 open section beams at elevated temperature, Thin-Walled Structures. 2016, vol. 98, Part A, no. 1, p. 2-18. ISSN 0263-8231.

SCI, Design manual for structural stainless steel, Silwood Park, Ascot, Berkshire. SL5 7QN UK, ISBN 13: 978-1-85942-226-7 